\title{
NANOPARTICLE RESEARCH ON FOUR GASOLINE CARS
}

\author{
Jan Czerwinski, Pierre Comte \\ University of Applied Sciences, Biel-Bienne, Switzerland (AFHB) \\ Gwerdtstrasse 5, 2560 Nidau, Suisse \\ tel.: +413232266 80, fax: +41323226681 \\ e-mail:jan.czerwinski@bfh.ch
}

Andreas Mayer

Technik Thermische Maschinen (TTM)

Fohrhölzlistrasse 14b, CH-5443 Niederrohrdorf

tel.: +415649664 14, fax: +41564966415

e-mail:ttm.a.mayer@bluewin.ch

\begin{abstract}
The invisible nanoparticles (NP) from combustion processes penetrate easily into the human body through the respiratory and olfactory ways and carry numerous harmful health effects potentials.

$N P$ count concentrations are limited in EU for Diesel passenger cars since 2013 and for gasoline cars with direct injection (GDI) since 2014. The limit for GDI was temporary extended to $6 \times 10^{12} \# / \mathrm{km}$.

Nuclei of metals as well as organics are suspected to significantly contribute especially to the ultrafine particle size fractions, and thus to the particle number concentration.

In the present paper, some results of investigations of nanoparticles from four gasoline cars - an older one with MPI and three never with DI - are represented. The measurements were performed at vehicle tailpipe and in CVS-tunnel.

The results show that the older vehicle with MPI emits high particle count concentrations. The size distributions of this vehicle are decisively bimodal with high numbers in nuclei mode.

The emissions of the newer vehicles with DI show sometimes no typical uniform shape of particle size distributions and are at lower level, than for the older vehicle. There is no visible nuclei mode and the ultrafine particle concentrations below $10 \mathrm{~nm}$ are insignificant.

Some of the newer, low-emitting vehicles show at constant speed operation a periodical fluctuation of the NPemissions.

Increased NP-emissions at cold start were confirmed.
\end{abstract}

Keywords: gasoline cars, combustion engine, nanoparticles measurements (NP), NP fluctuation

\section{Introduction}

The nanoaerosol in vehicle exhaust is known to be a complex mixture of different volatile and non-volatile species often showing a bimodal particle size distribution with a nucleation mode smaller than $20 \mathrm{~nm}$ and a larger accumulation mode that mainly contains aggregates of primary particles.

The larger accumulation mode is usually composed of more graphitic soot particles with an elemental carbon (EC) structure, whereas the particles in the nucleation mode are reported to be mainly volatile organics, especially when sulphur is absent from fuel and lubrication oil, [1-4]. However, recent studies detected also low-volatility particle fractions in the ultrafine size range when sampling was carried out according to PMP protocol at $300{ }^{\circ} \mathrm{C}$ [5-7].

Knowledge about the emission level, chemistry, and formation mechanisms of these particles is an important objective in order to assess their toxic potential, and to propose effective measures to reduce these emissions. 
Studies for gasoline fuelled internal combustion engines pointed out that also this vehicle class can emit remarkable amounts of particles. Especially gasoline direct injection technology (GDI) shows particle number (NP) emissions significantly higher than modern diesel cars equipped with best available DPF technology. Since the trend for gasoline vehicles with GDI technology is increasing, a significant rise in emission is predicted in the near future.

The investigations in present paper were performed at AFHB (Laboratories for IC-Engines and Exhaust Emission Control of the Berne University of Applied Sciences, Biel CH).

The presented topics are:

- comparison of SMPS particle size distributions of the vehicles at a stationary part load operation,

- NP-emissions in driving cycles cold \& warm,

- repetitivity of NP-emissions,

- emission dispersion at constant operation,

- comparisons of NP-emissions in legal driving cycles.

\section{Test vehicles}

The research of NP-emissions of a vehicle with MPI (older technology) and of the recent vehicles with GDI was performed on Renault 18 and Audi A3, Fig. 1 and Tab. 1 and Volvo V60 and Citroën C5, Fig. 2 and Tab. 2.
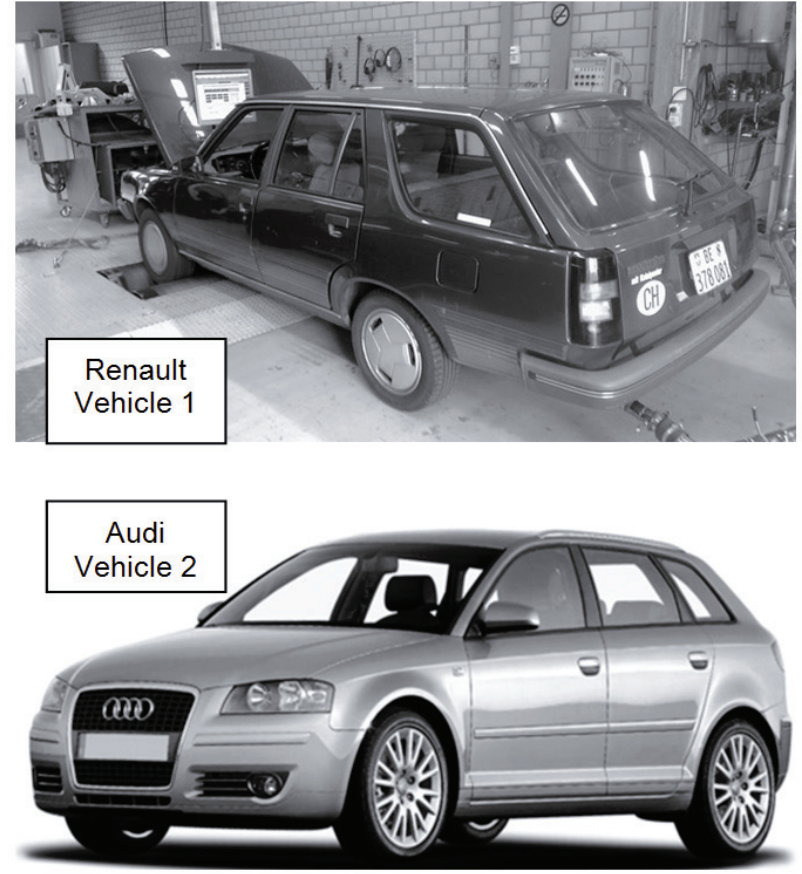

Fig. 1. Gasoline vehicles for research of NP

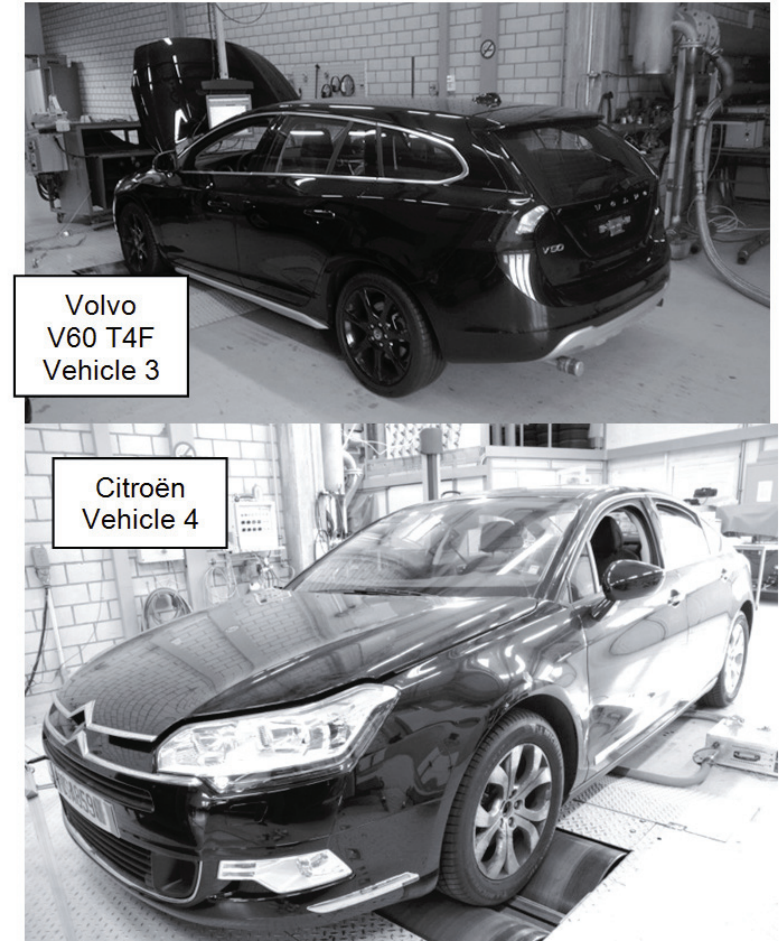

Fig. 2. Gasoline vehicles for research of NP

The gasoline used was from the Swiss market, RON 95, according to SN EN228.

In the present tests, the lube oils were not changed and not analysed.

\section{Test methods and instrumentation}

The vehicles were tested on a chassis dynamometer at constant speeds and in the dynamic driving cycles NEDC \& WLTC, with cold \& warm engine. 
Tab. 1. Data of vehicles Renault \& Audi

\begin{tabular}{|c|c|c|}
\hline Vehicle & Renault 18 Break & $\begin{array}{l}\text { Audi A3 } \\
\text { 2.0 TFSI }\end{array}$ \\
\hline Engine code & J7T-718 & BWA \\
\hline $\begin{array}{l}\text { Number and arrangement of } \\
\text { cylinders }\end{array}$ & $4 /$ in line & 4 / In line \\
\hline Displacement $\mathrm{cm}^{3}$ & 2164 & 1984 \\
\hline Power kW & $\begin{array}{c}74 @ 5000 \\
\text { rpm }\end{array}$ & $147 @ 6000$ rpm \\
\hline Torque Nm & $\begin{array}{c}162 @ 2000 \\
\text { rpm }\end{array}$ & $280 @ 1800$ rpm \\
\hline Injection type & MPI & DI \\
\hline Curb weight kg & 1110 & 1530 \\
\hline Gross vehicle weight $\mathrm{kg}$ & 1585 & 1920 \\
\hline Drive wheel & $\begin{array}{l}\text { Front-wheel } \\
\text { drive }\end{array}$ & Front-wheel drive \\
\hline Gearbox & $\mathrm{m} 5$ & $\mathrm{~m} 6$ \\
\hline First registration & 01.04 .1985 & 01.12 .2006 \\
\hline Exhaust & EURO 0 & EURO 4 \\
\hline VIN & $\begin{array}{l}\text { VF1135B00F } \\
0000505\end{array}$ & WAUZZZ8P17A042987 \\
\hline
\end{tabular}

Tab. 2. Data of vehicles Volvo \& Citroën

\begin{tabular}{|l|c|c|}
\hline Vehicle & $\begin{array}{c}\text { Volvo V60 } \\
\text { T4F }\end{array}$ & Citroën C5 \\
\hline Engine code & B4164T2 & EP6CDT (5F02) \\
\hline $\begin{array}{l}\text { Number and arrangement of } \\
\text { cylinder }\end{array}$ & $4 /$ in line & $4 /$ In line \\
\hline Displacement cm ${ }^{3}$ & 1596 & 1598 \\
\hline Power kW & $\begin{array}{c}132 @ 5700 \\
\text { rpm }\end{array}$ & $115 @ 6000 \mathrm{rpm}$ \\
\hline Torque Nm & $\begin{array}{c}240 @ 1600 \\
\text { rpm }\end{array}$ & $240 @ 1400-4000 \mathrm{rpm}$ \\
\hline Injection type & DI & DI \\
\hline Curb weight kg & 1554 & 1515 \\
\hline Gross vehicle weight kg & 2110 & 1951 \\
\hline Drive wheel & Front-wheel drive & Front-wheel drive \\
\hline Gearbox & a6 & a6 \\
\hline First registration & 27.01 .2012 & EURO 5a \\
\hline Exhaust & EURO 5a & VF7RD5FVABL503114 \\
\hline VIN & YV1FW075BC1043598 & . \\
\hline
\end{tabular}

The driving resistances of the test bench were set according to the legal prescriptions, responding to the horizontal road.

Nanoparticle analysis

The measurements of NP size distributions were conducted with different SMPS-systems, which enabled different ranges of size analysis:

- SMPS: DMA TSI 3081 \& CPC TSI 3772 (9.8-429 nm),

- nSMPS (AFHB): nDMA TSI 3085 \& CPC TSI $3772(6.85-85 \mathrm{~nm})$. 
For the dilution and sample preparation, an ASET system from Matter Aerosol was used, (ASET aerosol sampling \& evaporation tube).

This system contains:

- Primary dilution air - MD19 tunable mini-diluter (Matter Eng. MD19-2E),

- Secondary dilution air - dilution of the primary diluted and thermally conditioned measuring gas on the outlet of evaporative tube,

- Thermoconditioner (TC) - sample heating at $300^{\circ} \mathrm{C}$.

In the tests, the gas sample for the NP-analysis was taken from the undiluted exhaust gas at tailpipe or from the diluted exhaust gas in CVS-tunnel.

\section{Results}

SMPS particle size distributions (PSD) of all tested vehicles at tailpipe are represented exemplary at similar constant part load operation of the engine in Fig. 3.

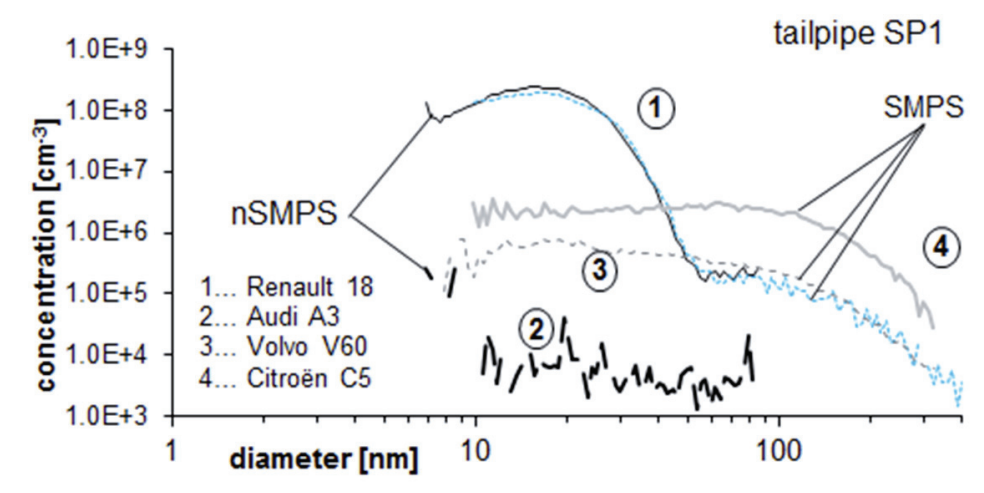

Fig. 3. Particle size distributions of different vehicles at tailpipe \& $40 \mathrm{~km} / \mathrm{h}$

The PSD's were measured with two SMPS-systems in different size ranges: SMPS [9.8-429 nm] and nSMPS [6.85-85 nm], which for vehicle 1 gives a very complementary picture of PSD's.

It can be remarked, that vehicle 1, the older model with MPI, has a clearly bimodal shape of PSD with maximum in nuclei mode, which is up to 4 orders of magnitude higher, than the lowest emissions of vehicle 2 .

The NP-emissions of vehicle 2 are at the ambient level and show stochastic peaks at different particle sizes, but no regular PSD.

The PSD's of vehicles $3 \& 4$ show no increased nuclei mode $(<50 \mathrm{~nm})$. In the accumulation mode $(>50 \mathrm{~nm})$ the particle count concentrations $(\mathrm{PC})$ of vehicle 3 are nearly identical with vehicle 1 and for vehicle 4 the PC's are up to 1 order of magnitude higher.

How can the differences be explained? There are different interacting processes during mixture preparation, combustion and gas flow in the exhaust system, which sensitively influence the generation of nanoparticle emissions. The following discussion gives some ideas and hypotheses:

For the older vehicle, it is clear that it has higher lube oil consumption than the other new vehicles. The lube oil consumption in such self-aspirating engine can be provoked by the valve shafts and by the used piston segments and cylinder walls. We can suppose the presence of both reasons: the lube oil from intake valves shafts will be carried with the fuel (MPI) into the combustion chambers, the thicker lube oil layer on the combustion chamber walls will contribute to higher induction of oil into the combustion. Both effects work similarly like the blending of lube oil into the fuel for lost-oil-lubrication of small 2-stroke engines and increases strongly the NP-emissions, [8]. This increase is caused on the one hand by metal and metal oxides from the additive packages, which during the spontaneous condensation produce primary particles in nano-, or sub-nano scale. These primary particles are on the other hand "seeding kernels" for the 
condensation of heaviest HC-compounds from the lube oil, which can pyrolyze, and cannot be eliminated by the catalytic or thermal striping used in the present measuring systems.

Another question is the mixture preparation: the ideal mixture preparation should atomize and evaporate all the used fuel and bring it as homogenously premixed, as possible into the combustion chamber.

For MPI there is usually a portion of fuel deposited on the walls of the intake port, which can arrive in the combustion chamber as liquid non-premixed droplets. A part of this "unprepared" fuel burns heterogeneously and is a source of soot-production.

These effects are stronger in DI technology and especially, when the liquid fuel arrives at the wall and interacts with the lube oil layer, the production of nanoparticles is particularly increased. The chemistry of oil and fuel, their HC-matrix and additive packages have a significant influence on the NP's.

The passage of aerosol through the exhaust system, the history of temperature drop, catalysis, chemistry, spontaneous condensation and store/release effects have finally influences on "what will be measured at tailpipe."

The processes influencing NP-production depend on engine operating conditions. With no doubt the NP-emissions vary with the operating point and are increased at transient operation. Further figures represent some results of summary NP-counts, measured with CPC in the legal driving cycles NEDC \& WLTC.

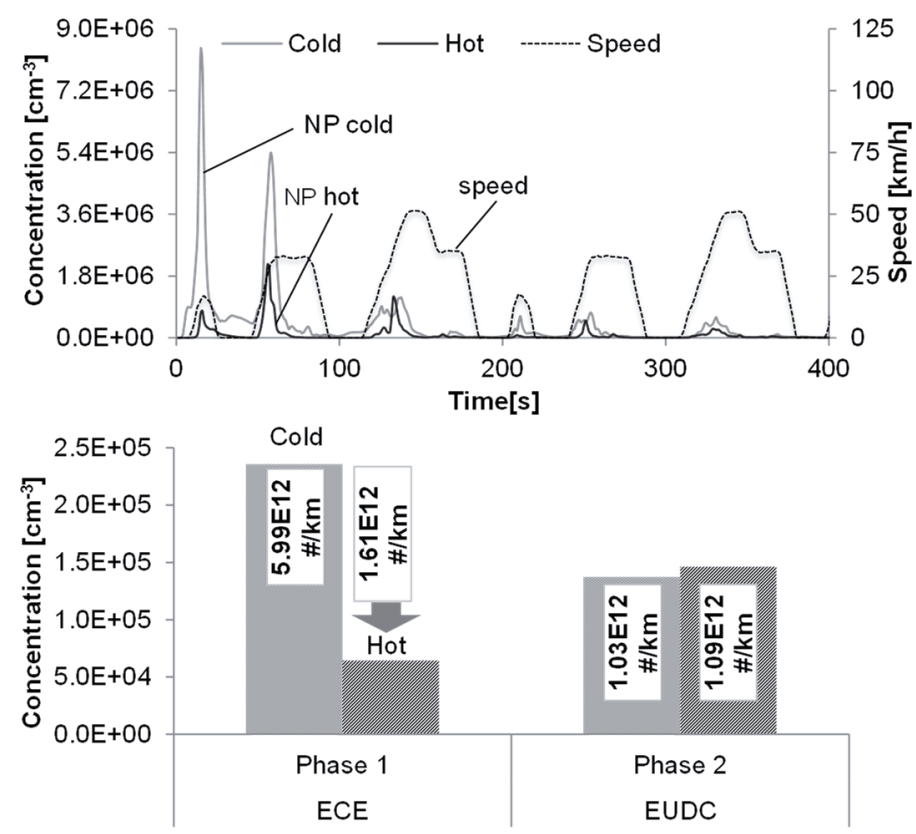

Fig. 4. Comparison of NP-Emissions in NEDC cold and hot. Vehicle 3; CVS tunnel

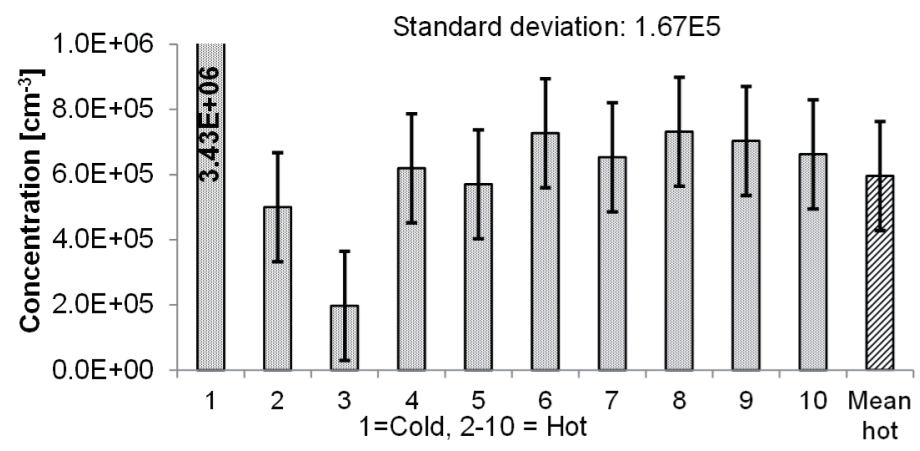

Fig. 5. Repeatability of NP-Emissions in subsequent NEDC's. Vehicle 3; tailpipe 
Figure 4 - the NP emitted at cold start $\left(20-25^{\circ} \mathrm{C}\right)$ of a NEDC are roughly 4 times higher than with the hot start. There is only a little dispersion of results from two different days.

There is a good repeatability of average PC-emissions in NEDC's hot, Fig. 5. The cycle with cold start has higher emissions, as already remarked in the previous reference tests.

It has to be remarked that the cycles $2 \& 3$ were performed with less vehicle cooling, due to temporary malfunction of the driving ventilator. This caused lower NP-emissions and also high CO-emissions in these cycles. It is to be reminded that the gaseous emissions of this modern vehicle are very low.

Five WLTC's - 1 cycle with cold start and 4 cycles with warm start - were performed with the objective of indicating the repetitivity of NP-emissions.

The nanoparticles were measured on line with CPC at the end of CVS-tunnel (according to the PMP-method).

Figure 6 represents the PN-concentrations for all WLTC cycles with the zoomed representations of some interesting periods. During the first accelerations in the cold-cycle, there are high NP-emissions peaks. In the other warm periods of the cycles the NP-emissions are mostly well repeatable. Exceptions are sometimes at high acceleration events, where the store/release effects may overlap the emission results.
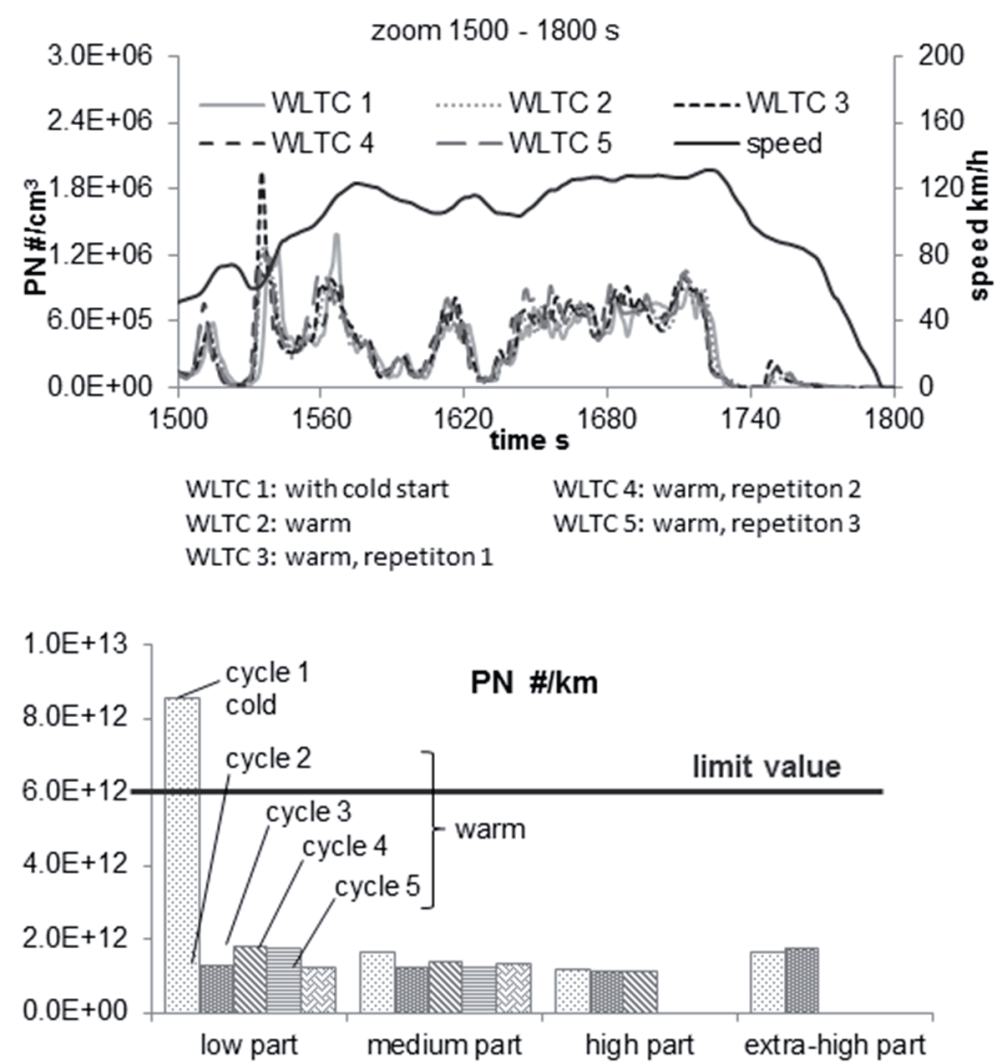

Fig. 6. NP-Emissions in WLTC cold and hot. Vehicle 3; CVS tunnel

The average emission results are presented at the bottom of this figure. On the chassis dynamometer were only 3 dilution bags available, so the measurements were performed alternatively for high or extra-high cycle phase.

There is a good repeatability of the average emissions in the WLTC's warm.

During some tests at constant vehicle speed, the NP-signals (DC, or CPC) were on-line registered. Fig. 7 demonstrates the periodically fluctuating emissions of NP during the constant operation of vehicles $3 \& 4$.

This periodical fluctuation is a result of regulation of the complex engine electronic systems. 


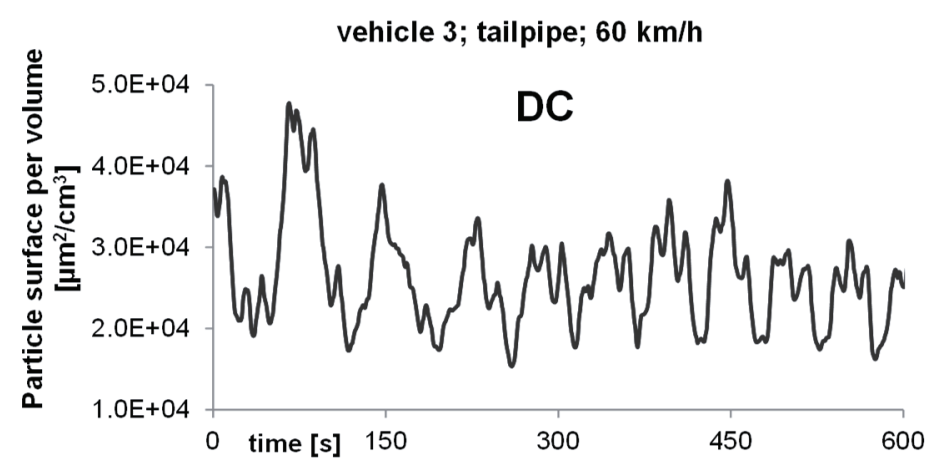

vehicle 4; (engine: BMW Valvetronic, double VANOS); tailpipe; $50 \mathrm{~km} / \mathrm{h}$

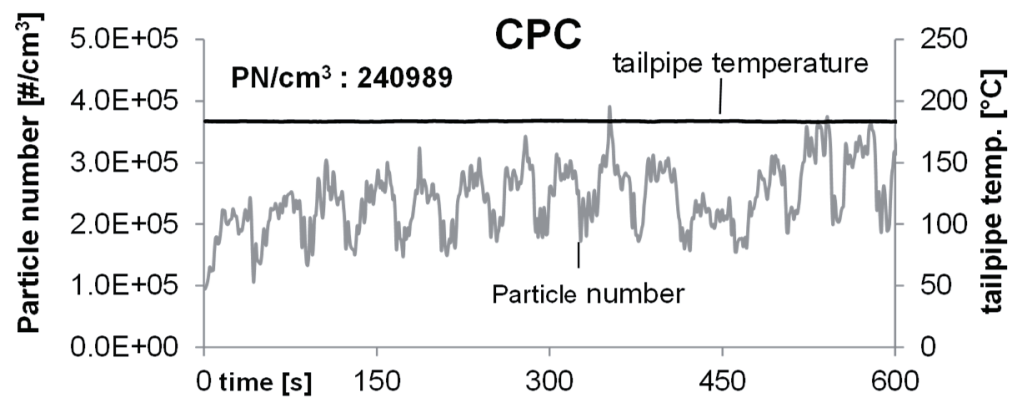

Fig. 7. NP-emission dispersion over time
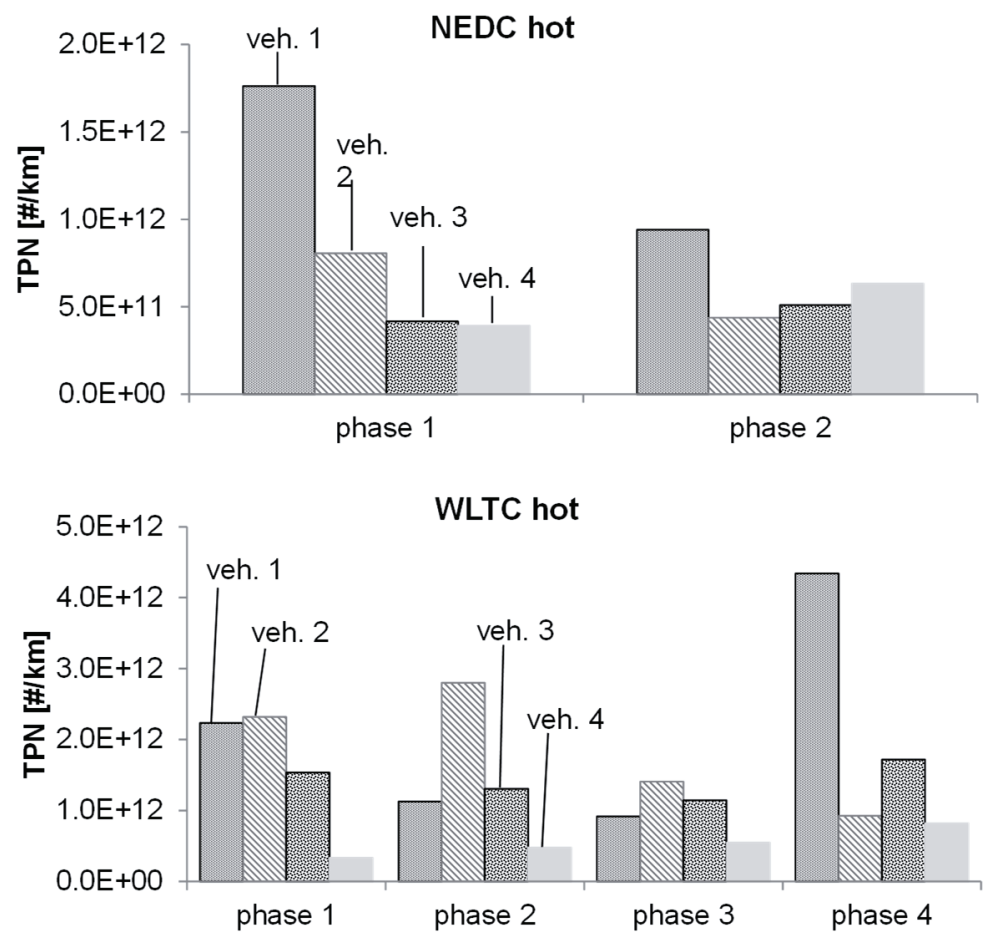

Fig. 8. Comparisons of NP-results in NEDC hot. CVS tunnel; gasoline

Figure 8 compares the total particle number emissions TPN of all vehicles in the driving cycles NEDC \& WLTC "hot." In both phases of NEDC vehicle 1 has the highest emissions.

Regarding from phase 1 (ECE) to phase 2 (EUDC with higher load) the relationship of vehicles $2,3 \& 4$ inverts.

In WLTC vehicle 2 becomes in some phases of the cycle higher emitting than the other vehicles, in spite of showing previously very low emissions at constant speeds (see Fig. 3). It is 
visible that the NP-emissions of each vehicle depend on the dynamics and power of the used driving cycle. The consideration of SMPS PSD's at certain constant operation (like in Fig. 3) is not sufficient to see the relationships at transient operation in the presented driving cycles.

\section{Conclusions}

The most important statements can be summarized as follows:

- the older model with MPI (vehicle 1) emits at the stationary part load operation up to 4 orders of magnitude more nanoparticles,

- for the low-emitting vehicle there are sporadic NP-emission peaks and no clear shape of particle size distribution,

- for the vehicles with DI (vehicle 2, $3 \& 4$ ) there is no increase of PC's in nuclei mode (below $10 \mathrm{~nm})$ at the measured constant speeds,

- the NP emitted at cold start $\left(20-25^{\circ} \mathrm{C}\right)$ of a NEDC, or WLTC are roughly 4 to 5 times higher than with the hot start,

- in the last phases of WLTC with higher accelerations, with higher speeds and more energy needed for accelerations, there is a highest level of NP-emissions,

- there is a good repeatability of the average emissions in the "warm" driving cycles, due to the electronic regulation of the engine the NP-emission of some vehicles (here vehicle $3 \& 4$ ) are periodically fluctuating,

- comparing the NP-emissions of different vehicles with SMPS PSD's at constant operation gives only a limited information about the relationships of emissions measured with $\mathrm{CPC}$ in dynamic driving cycles.

\section{Acknowledgements}

The authors want to express their gratitude to the institutions, which financially supported the activities: Swiss Federal Office of Environment, Swiss Federal Office of Energy, Swiss Oil and Swiss Lubes.

\section{References}

[1] Sgro, L. A., et al., Investigating the origin of nuclei particles in GDI engine exhausts, Combustion and Flame, 159(4): pp. 1687-1692, 2012.

[2] Burtscher, H., Physical characterization of particulate emissions from diesel engines: a review, Journal of Aerosol Science, 36(7): pp. 896-932, 2005.

[3] Ulrich, A., Wichser, A., Analysis of additive metals in fuel and emission aerosols of diesel vehicles with and without particle traps, Analytical and Bioanalytical chemistry, 377(1): pp. 71-81, 2003.

[4] $\mathrm{Hu}, \mathrm{S}$., et al., Metals emitted from heavy-duty diesel vehicles equipped with advanced PM and NOX emission controls, Atmospheric Environment, 43(18): pp. 2950-2959, 2009.

[5] Mayer, A., Czerwinski, J., Ulrich, A., Mooney, J. J., Metal-Oxide Particles in Combustion Engine Exhaust, SAE Technical Paper 2010-01-0792, 2010.

[6] Mayer, A., Czerwinski, J., Kasper, M., Ulrich, A., Mooney, J. J., Metal Oxide Particle Emissions from Diesel and Petrol Engines, SAE Technical Paper 2012-01-0841, 2012.

[7] Ulrich, A., et al., Particle and metal emissions of diesel and gasoline engines are particle filters appropriate measures? Proceedings of the 16th ETH Conference on Combustion Generated Nanoparticles 2012.

[8] Czerwinski, J., Comte, P., Astorga, C., Rey, M., Mayer, A., Reutimann, F., (Nano) Particles from 2-S Scooters: SOF / INSOF; Improvements of Aftertreatment, Toxicity, AFHB, JRC, TTM, BAFU, SAE Techn. Paper 2007-01-1089, 2007. 
Abbreviations

AFHB Abgasprüfstelle FH Biel, $\mathrm{CH}$

ASET Aerosol Sampling \& Evaporation Tube

BAFU Bundesamt für Umwelt, (see FOEN)

CLA chemiluminescent analyser

CPC condensation particle counter

CVS constant volume sampling

DF dilution factor

DI Direct Injection

DMA differential mobility analyser

ECE Economic Commission for Europe

EMPA Eidgenössische Material Prüf- und Forschungsanstalt

EUDC Extra Urban Driving Cycle

FHNW Fachhochschule Nord-West Schweiz

FOEN Federal Office for Environment

GasOMeP Gasoline Organic \& Metal Particles

GDI gasoline direct injection

MD minidiluter

MFS mass flow sensor

NEDC New European Driving Cycle

NP nanoparticles $<999 \mathrm{~nm}$

nSMPS nano SMPS

PC particle counts (integrated)

PN particle numbers

PSD particle size distribution

PSI Paul Scherrer Institute

SMPS scanning mobility particle sizer

SP sampling position

TC thermoconditioner

TTM TechnikThermische Maschinen

WLTC Worldwide Light Duty Test Cycle 